\title{
Use of routinely collected data on trihalomethane in drinking water for epidemiological purposes
} T Keegan, H Whitaker, M J Nieuwenhuijsen, M B Toledano, P Elliott, J Fawell,
M Wilkinson, N Best

\begin{abstract}
Objectives-To explore the use of routinely collected trihalomethane (THM) measurements for epidemiological studies. Recently there has been interest in the relation between byproducts of disinfection of public drinking water and certain adverse reproductive outcomes, including stillbirth, congenital malformations, and low birth weight.
\end{abstract}

Method-Five years of THM readings (1992-6), collected for compliance with statutory limits, were analysed. One water company in the north west of England, divided into 288 water zones, provided 15984 observations for statistical analysis. On average each zone was sampled 11.1 times a year. Five year, annual, monthly, and seasonal variation in THMs were examined as well as the variability within and between zones.

The TH Huxley School of the Environment, Earth Sciences and Engineering, Imperial College of Science Technology and Medicine, RSM Prince Consort Road, London SW7 2BP, UK

T Keegan

M J Nieuwenhuijsen

Small Area Health

Statistics Unit,

Department of

Epidemiology and

Public Health, Imperial College of

Medicine at St Mary's,

London W2 1PG, UK

$\mathrm{H}$ Whitaker

M J Nieuwenhuijsen

M B Toledano

P Elliott

N Best

North West Water, Thirlmere House, Lingley Mere, Great Sankey, Warrington

WA5 3LP, UK

$\mathrm{M}$ Wilkinson

Warren Associates, 8 Prince Maurice Court, Devizes,

Wiltshire SN10 2RT, UK

J Fawell

Correspondence to:

Dr M J Nieuwenhuijsen

m.nieuwenhuijsen@ic.ac.uk

Accepted 14 March 2001 reduced considerably, which suggests that successful improvements in treatment have been made to reduce high TTHM concentrations in the area. For chloroform and BDCM, the main THMs, the component between water zones was greater than variation within water zones and explained most of the overall exposure variation. Variation between months and seasons was low and showed no clear trends within years. The results indicate that routinely collected data can be used to obtain exposure estimates for epidemiological studies at a small area level. (Occup Environ Med 2001;58:447-452)

Keywords: chlorination byproducts; exposure; birth outcomes; routine data; trihalomethanes

There is growing concern over the effects of disinfection byproducts of chlorination on human health. Early studies investigated links between disinfection byproducts of chlorination and increased risk of certain cancers, such as rectal, bladder, and colon cancer. ${ }^{1}$ More recent studies have focused on the possible effects of disinfection byproducts of chlorination on certain reproductive outcomes, including low birthweight, stillbirth, spontaneous abortion, and congenital abnormalities. The results from these studies have been mixed. ${ }^{23}$

Several of these reproductive epidemiological studies relied on crude exposure data. Some used comparisons between water source (ground $v$ surface) and between water treatments (chlorinated $v$ non-chlorinated). ${ }^{45}$ Others have used routinely collected total trihalomethane (TTHM) measurements to form exposure categories. ${ }^{6-9}$ More recent studies have attempted to measure individual exposure with routinely collected THM measurements combined with a measure of ingestion such as number of glasses or water drunk per day. ${ }^{10-13}$ Misclassification of exposure as a result of crude exposure assessment may lead to biased risk estimates, which makes it more difficult to interpret the studies. ${ }^{14}$

Trihalomethanes (THMs), and many other disinfection byproducts of chlorination, are formed when chlorine reacts with naturally occurring organic substances present in water. They are generally the most common byproducts. It is thought that THM concentrations vary both temporally and spatially. ${ }^{15}{ }^{16}$ In the water company under study much of the supply is upland surface water, which has higher concentrations of THM precursors than water drawn predominantly from aquifers. Surface water sources are more likely to produce chlorinated THMs, whereas treated water from 
ground water sources can produce higher concentrations of brominated THMs.

Water companies in the United Kingdom divide the area under their control into water supply zones, hydraulically defined in such a way that the quality of drinking water on entry to a zone would be the same for all consumers within that zone. These zones form the basis for monitoring the water quality of drinking water so they define populations of consumers to which routinely collected water data can be related. The water in each water zone is tested a minimum of four times a year to comply with the TTHM regulatory standard. Of all the disinfection byproducts, only THM concentrations are currently regulated, although they are not the only class of disinfection byproduct suggested as having adverse reproductive effects. Haloacetic acids, haloacetonitriles, and acetonitriles have also been implicated. ${ }^{3}{ }^{17}$

To assess the effect of THM exposure concentrations on certain reproductive outcomes, routinely collected quarterly (seasonal) THM concentrations could be attached to a pregnancy trimester of women living in the water zone, but such exposure information would generally be based on only one measurement, and given the variation in exposure, that might be unreliable. Annual averages would provide more precise THM means, but would be based on perhaps four measurements and might not reflect exposure for any 3 month period within that year. A 5 year average THM concentration would be based on more measurements (between 20 and 60), but might be insensitive to timing of exposures relevant to birth outcomes.

The purpose of this study was to explore routinely collected THM data for use in epidemiological studies and to determine the best measure of THM exposure. The specific aims of this study were to examine; (a) the current exposure concentrations of TTHM and individual THMs in tap water in the north west area, (b) the correlation between TTHMs and individual THM concentrations, $(c)$ the variability of total and individual THM concentrations between and within zones, seasons, months, and years. This will provide information to enable choice of the most appropriate routinely available exposure estimate for epidemiological studies, in particular reproductive health studies.

\section{Methods}

THE DATA

Routinely collected data on TTHM concentrations were obtained from a United Kingdom water company in the north of England for the period 1992-6. Information was also obtained on the geography of the supply zones, the type of water each receives and the population each supplies.

DATA COLLECTION

Four THMs are routinely measured by United Kingdom water companies. They are chloroform, bromodichloromethane (BDCM), dibromochloromethane (DBCM), and bromoform. Their concentrations in public drinking water are measured in samples from randomly selected taps in each water zone. The sum of the concentrations of the four individual THMs is the TTHM concentration. Under the Water Supply (Water Quality) (1989) Regulations, the water companies are required to collect four samples/year/water zone. The statutory limit for TTHMs is $100 \mu \mathrm{g} / 1$ as a rolling 3 month average. Exceedance of the limit requires monthly measurements to be taken until the TTHM concentrations decrease. In many zones monthly measurements are taken routinely for operational purposes.

WATER SUPPLY (OR COMPLIANCE) ZONES

Water zones differ in area, in the number of people each serves, and in the volume of water passing through each per day. Small, rural zones may serve 300 people $70 \mathrm{kl}$ per day, whereas others may deliver as much as 16000 $\mathrm{kl}$ per day to 50000 people. The main water sources in the area are Thirlmere and Ullswater in the Lake District. Only 6\% of zones are supplied exclusively by groundwater. The number of water zones may change. In north west England during 1992 there were 313 zones, in 1993 316, in 1994 317, in 1995 and 1996323. Some of the new zones were created whole, whereas some were split from existing zones. It was decided to omit the data from all zones created after 1992, from all zones created from existing zones, and from the zones from which these were split. Only zones in which boundaries and source did not change over the study period and for which 5 years' worth of data were available were included. For the statistical analysis, this left 288 water zones supplied by 194 treatment works, serving about 6.8 million people.

\section{LABORATORY ANALYSIS}

Water samples were analysed by the water company with a capillary gas chromatograph with an electron captive detector. The detection limit was $2.5 \mu \mathrm{g} / 1$ for all THMs. The water company runs internal and external quality control tests and is accredited by the United Kingdom Accreditation Service (UKAS). The quality of the THM data is audited by the United Kingdom Drinking Water Inspectoarate.

\section{STATISTICAL ANALYSIS}

Descriptive analyses were carried out to calculate over time the zone means for total and individual THMs plus correlation coefficients between individual and total THMs. The distribution of the TTHMs could be best described with a normal distribution. However, the distributions of the individual THMs were positively skewed. No statistical analysis of the bromoform data was attempted as most of the readings $(95 \%)$ were below the detection limit.

To find within and between zone variation the individual THM data were first transformed with Box-Cox transformations. ${ }^{18}$ This provided approximately normally distributed values. These were then analysed with a multilevel (variance components) model to estimate the mean and variance within and between 
Table 1 Means of the zone TTHM concentrations $(\mu \mathrm{g} / \mathrm{l})$ in the north west of England, 1992-6

\begin{tabular}{llllrr}
\hline Year & AM & SD & Min & Max & \multicolumn{1}{l}{$n$} \\
\hline 1992 & 46.6 & 22.6 & 6.6 & 142.2 & 290 \\
1993 & 48.9 & 22.7 & 6.6 & 111.0 & 297 \\
1994 & 49.9 & 22.8 & 6.6 & 102.4 & 299 \\
1995 & 46.1 & 19.9 & 6.6 & 91.6 & 304 \\
1996 & 46.9 & 18.8 & 6.6 & 88.0 & 304 \\
$1992-6$ & 47.6 & 21.4 & 6.6 & 142.2 & 1494
\end{tabular}

$\overline{\mathrm{AM}}=$ Arithmetic mean $(\mu \mathrm{g} / \mathrm{l}) ; \mathrm{Min}=$ minimum zone TTHM mean $(\mu \mathrm{g} / \mathrm{l}) ;$ Max=maximum zone TTHM mean $(\mu \mathrm{g} / \mathrm{l})$; $\mathrm{n}=$ number of observations; TTHM=total trihalomethane.

zones for each THM on the transformed scale. ${ }^{19}$ This modelling was necessary to provide more reliable estimates of the variation within the zones with few data.

It is more meaningful to report estimates of the variation on the scale of the original data rather than on the scale of the transformed data. However, the variance may be a misleading summary on the original scale as the distributions were skewed. An alternative measure of the spread of the distributions within and between zones can be provided by the interquartile range (IQR). This is simply the difference between the upper and lower quartiles,

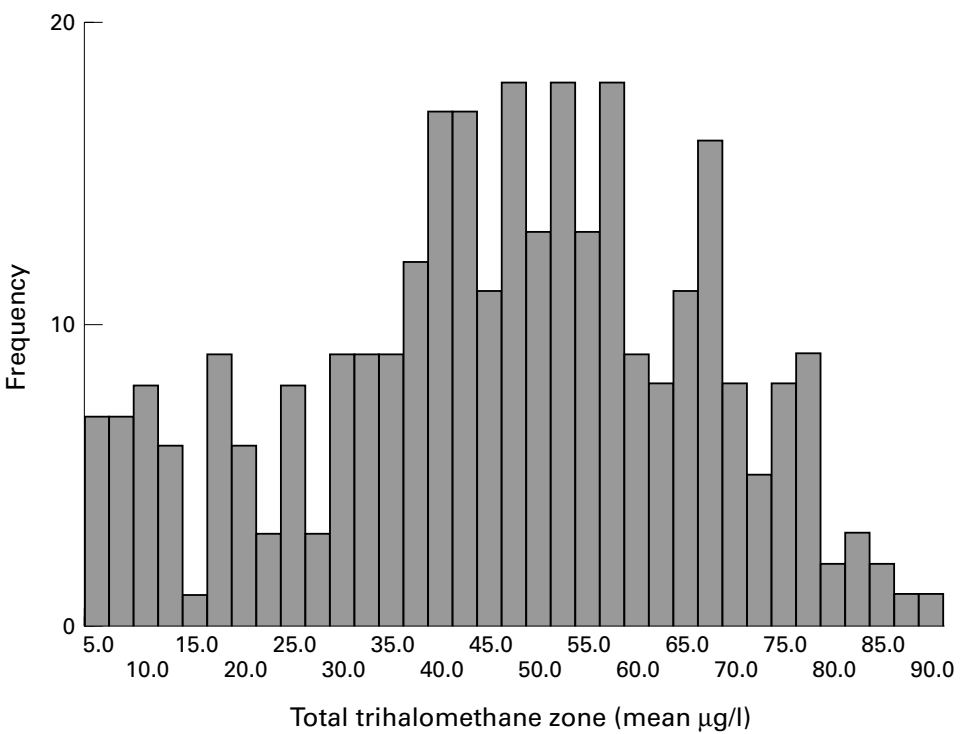

Figure 1 Frequency distribution of 5 year total trihalomethane zone means, north west of England 1992-6.

Table 2 Characteristics of individual THM concentrations ( $\mu \mathrm{g} / \mathrm{l})$ in the north west of England

\begin{tabular}{lcccccccc}
\hline & Year & AM & SD & GM & GSD & Min & Max & $<$ dl (\%) \\
\hline Chloroform & 1992 & 34.7 & 20.4 & 25.5 & 3.0 & 1.6 & 118.3 & 6.2 \\
& 1993 & 37.2 & 21.2 & 29.0 & 3.1 & 1.6 & 97.1 & 8.6 \\
& 1994 & 37.8 & 22.1 & 31.2 & 2.7 & 1.6 & 91.7 & 5.6 \\
& 1995 & 33.4 & 23.2 & 27.7 & 2.6 & 1.6 & 77.8 & 6.2 \\
BDCM & 1996 & 33.6 & 21.6 & 26.0 & 2.7 & 1.6 & 73.5 & 7.5 \\
& 1992 & 7.7 & 3.2 & 7.2 & 2.0 & 1.6 & 19.7 & 12.2 \\
& 1993 & 7.5 & 3.1 & 7.2 & 1.9 & 1.6 & 17.2 & 11.0 \\
& 1994 & 7.4 & 3.1 & 7.0 & 1.8 & 1.6 & 14.5 & 8.6 \\
& 1995 & 7.8 & 3.7 & 7.4 & 1.8 & 1.6 & 15.8 & 7.6 \\
DBCM & 1996 & 8.2 & 3.8 & 7.5 & 1.8 & 1.6 & 17.1 & 9.4 \\
& 1992 & 2.4 & 1.0 & 2.3 & 1.6 & 1.6 & 7.1 & 63.0 \\
& 1993 & 2.4 & 1.1 & 2.2 & 1.6 & 1.6 & 6.1 & 70.0 \\
& 1994 & 2.8 & 1.4 & 2.5 & 1.7 & 1.6 & 8.0 & 60.0 \\
& 1995 & 3.0 & 2.1 & 2.6 & 1.7 & 1.6 & 8.8 & 57.0 \\
& 1996 & 3.2 & 2.3 & 2.7 & 1.8 & 1.6 & 11.5 & 53.0 \\
\hline
\end{tabular}

Min=minimum THM concentration $\mu \mathrm{g} / 1$ (all set to $2 / 3$ detection limit); $<\mathrm{dl}(\%)=\%$ of readings below detection limit. Other abbreviations as in table 1 .

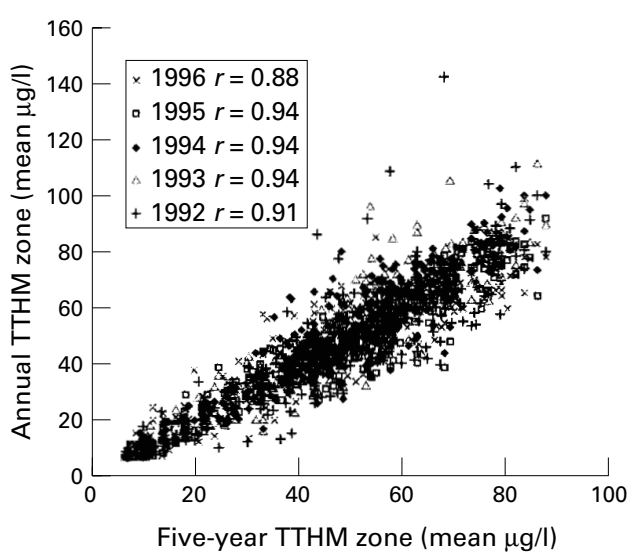

Figure 2 Five year total trihalomethane zone means plotted against annual total trihalomethane zone means.

giving the range of the middle half of the data, and makes no assumptions about the distribution of the data. Interquartile ranges within and between zones were therefore calculated for each transformed THM using the 25th and 75 th percentiles of the cumulative normal distribution based on the appropriate estimates of mean and variance from the multilevel model. These IQRs were then back transformed onto the original scale of the data.

\section{Results}

TTHM CONCENTRATIONS

The range of TTHM concentrations across all water zones was $1.65-188.7 \mu \mathrm{g} / \mathrm{l}$. The mean number of observations/water zone over 5 years was 55.5 , or 11.1 a year, although this ranged from a minimum of four to a maximum of 45 a year.

Over the 5 years the mean annual zone TTHM concentrations were very similar, and all were less than half the statutory limit of 100 $\mu \mathrm{g} / 1$ (table 1). The maximum zone TTHM mean fell by $38 \%$ over 5 years. Figure 1 shows the distribution of TTHM zone means.

INDIVIDUAL THM CONCENTRATIONS

Table 2 shows the zone means for individual THMs between 1992 and 1996. For chloroform, the means were similar over the years. For both BDCM and DBCM they rose slightly. The maximum recorded concentrations showed an increasing trend over the years. Most (95\%) bromoform measurements were below the detection limit and no analysis of its concentrations was undertaken.

CORRELATION BETWEEN YEARS

The mean annual zone TTHM concentration was plotted against the 5 year mean for each zone (fig 2) to assess the variation over the years. Overall the correlation between years was high $(r \geqslant 0.88)$. The correlation between the mean annual zone concentrations for the individual THMs was also high (chloroform $r=0.88, \mathrm{BDCM} r=0.87, \mathrm{DBCM} r=0.83)$.

CORRELATION BETWEEN INDIVIDUAL THM AND TTHM

Figure 3 shows the correlations between annual zone means of the individual THM concentrations and annual zone means of the 


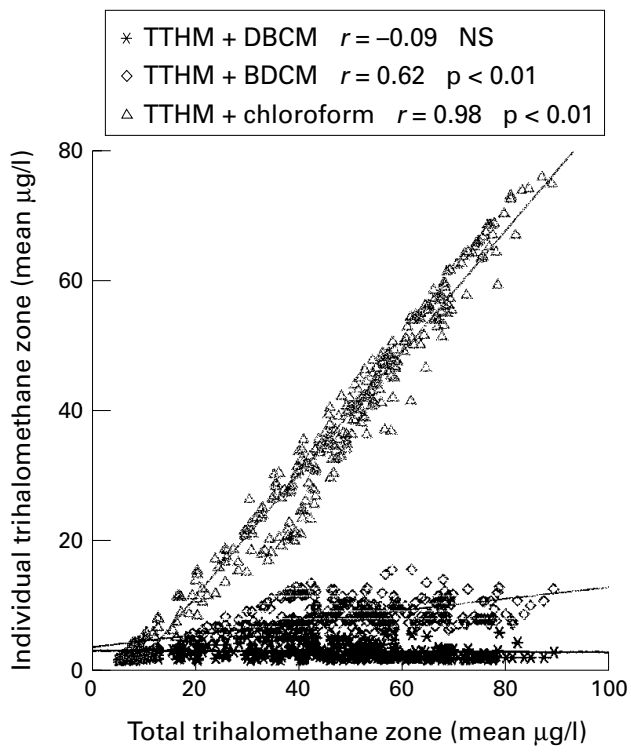

Figure 3 Zone means 1995. Scatter plot of individual THM zone means against total THM zone means.

TTHM concentrations for 1995. Chloroform correlated well with the TTHM $(r=0.98)$, but BDCM correlated less well with TTHMs $(r=0.62)$. There was no correlation between TTHM and DBCM.

VARIATION OF INDIVIDUAL THMS WITHIN AND BETWEEN ZONES

Table 3 shows the IQR between zones and a summary of the IQR for each distribution within a zone. For chloroform and BDCM the spread within zones is less than the spread between zones, particularly in later years. For DBCM, the mean of the IQRs within zones is greater than the IQR between zones for each year, but the medians of the IQRs within zones are lower. The IQRs within zones for chloroform and BDCM decrease throughout the 5 years, conversely the IQRs within zones for DBCM increase throughout the study period. For all three individual THMs, the ratio of the variation within zones to between zones increased throughout the study period.

\section{Discussion}

In this study we found that concentrations of TTHM in the north west of England were on average just under half the statutory limit of $100 \mu \mathrm{g} / \mathrm{l}$ between 1992 and 1996. Water zone means remained at a similar level over the 5 years. Concentrations of TTHMs correlated well with chloroform, the predominant THM, less well with BDCM, but not with DBCM. The variation between zones was generally larger than the variation within zones for chloroform and BDCM concentrations, in particular in later years, but not for DBCM concentrations. Models incorporating year, season, or month showed that none of these explained more than $3 \%$ of the total variation in TTHMs.

Water zone mean concentrations of TTHM were very similar over the years, but the maximum zone means fell from 142.2 to $88.0 \mu \mathrm{g} / \mathrm{l}$ (32\% reduction). This suggests that measures to reduce TTHM concentrations were well targeted towards the zones with the highest TTHM and have been successful in reducing high mean concentrations. Over the study period the variation within zones fell for chloroform and BDCM, and the variation between zones increased relative to the variation within zones. The fall in variability within each zone suggests that treatment methods became more efficient-for example, either at removing the THM precursor or at reducing THM formation in the network. The water company in this study introduced new technology into several treatment plants between 1992 and 1996 and this could have had some direct effect on stabilising the THM concentrations.

High variation between zones compared with variation within zones is desirable for geographical epidemiological studies. It is more likely that zone means are distinct from each other, and therefore there is less overlap in their distributions. In this case people living in different water zones would be exposed to distinctly different THM concentrations, which reduces the risk of exposure misclassification and bias in health risk estimates. Furthermore, when the variation within zones is small, zone

Table 3 Estimated interquartile ranges (IQRs) within and between zones for individual THMs ( $\mu g / l)$ in the north west of England

\begin{tabular}{|c|c|c|c|c|c|}
\hline$T H M$ & Year & $I Q R$ between zones & $\begin{array}{l}\text { Average IQR within } \\
\text { zones weighted by } \\
\text { number of } \\
\text { samples/zone }\end{array}$ & $\begin{array}{l}\text { Median IQR within } \\
\text { zones }\end{array}$ & $\begin{array}{l}\text { Percentage of IQRs } \\
\text { within zones that are } \\
\text { less than the IQRs } \\
\text { between zone }\end{array}$ \\
\hline \multirow[t]{5}{*}{ Chloroform } & 1992 & 27.4 & 24.9 & 23.5 & 74.7 \\
\hline & 1993 & 30.9 & 27.3 & 23.2 & 78.8 \\
\hline & 1994 & 32.2 & 21.9 & 19.6 & 92.3 \\
\hline & 1995 & 28.1 & 13.7 & 13.7 & 96.4 \\
\hline & 1996 & 26.8 & 16.7 & 15.2 & 93.8 \\
\hline \multirow[t]{5}{*}{ BDCM } & 1992 & 4.5 & 4.5 & 3.9 & 67.1 \\
\hline & 1993 & 4.3 & 4.4 & 3.8 & 66.0 \\
\hline & 1994 & 4.3 & 3.6 & 3.2 & 78.9 \\
\hline & 1995 & 4.6 & 3.1 & 2.84 & 94.1 \\
\hline & 1996 & 4.6 & 3.0 & 2.7 & 90.5 \\
\hline \multirow[t]{5}{*}{ DBCM } & 1992 & 0.7 & 1.1 & 0.6 & 57.4 \\
\hline & 1993 & 0.7 & 1.0 & 0.6 & 65.7 \\
\hline & 1994 & 1.0 & 1.2 & 0.8 & 61.1 \\
\hline & 1995 & 1.1 & 1.2 & 0.8 & 58.2 \\
\hline & 1996 & 1.22 & 1.3 & 0.7 & 61.5 \\
\hline
\end{tabular}


means are likely to be more precise, even with a few measurements.

Concentrations of TTHM varied only little by season suggesting that the annual mean may be a good estimate for various seasons. This contrasts with some other studies that have shown that TTHM concentrations vary considerably throughout the year. ${ }^{15} 1620$ We found that TTHM concentrations were generally lowest in the spring and highest at the end of summer and during the autumn, but there was a lack of consistency. Spring concentrations in some years were higher than autumn concentrations. ${ }^{21}$ An annual cycle would be consistent with the factors that affect the rate and quantity of THM formation; during the summer and autumn water temperatures are higher than in the winter and spring. Temperature is known to increase the rate of THM formation. ${ }^{15}$ Formation of THMs is also dependent on the quantity of organic precursors, and these are more abundant during the late summer and autumn, when there is increased leaching of organic matter from decaying vegetative matter. Improvements in treatment will also help to reduce the variation and this may explain our findings.

Our results showed that the correlation between yearly zone means and 5 year zone means was high, which suggests that there are areas where the THM concentrations are consistently high and consistently low in the region. This is a desirable feature for epidemiological studies as it reduces the potential for exposure misclassification.

In our study area the dominant THM was chloroform. In surface waters chloroform is often the most easily formed THM, followed by DCBM and DBCM. Bromoform is the least easily formed. ${ }^{15}$ This pattern of formation is reflected in their mean concentrations for 1995 and 1996, with chloroform existing at concentrations five times that of DCBM, 12 times that of DBCM, and 20 times that of bromoform. These ratios are consistent with those commonly found in chlorinated drinking water predominantly drawn from upland surface water sources. The high concentration of chloroform is consistent with the continued reaction of chlorine with organic matter and its production in preference to other THMs because of the low bromide content surface water. $^{20}$

Concentrations of TTHM were correlated most strongly with chloroform, then BDCM. There was no correlation with DBCM. These findings suggest that TTHM concentrations most accurately reflect chloroform concentrations, particularly in areas where surface waters represent the dominant water source. However, given that TTHM is a good indicator only of chloroform and not of the other individual THM concentrations, data on other individual THM concentrations, and possibly other disinfection byproducts of chlorination, would need to be incorporated into epidemiological studies to fully explore any potential health effects of those byproducts. This is important as different THMs may be associated with different health outcomes. ${ }^{32}$ For example
BDCM has been more strongly associated with spontaneous abortion than have other THMs. ${ }^{14}$

Over the study period the variations in chloroform and BDCM between zones were greater than the variations within zones. However, it should be pointed out that even in the year when variation between zones was at its highest (1996), a considerable proportion of the total variation was within zones. This variation within zones could be a result of real variability in THMs caused by changes in - for example, precursor concentrations, chlorine dose, residence time in the distribution system, water source, temperature, and $\mathrm{pH} .{ }^{20}$ Limited sampling in a zone with high variability in THMs could lead to imprecise estimates and therefore exposure misclassification when water zone means are linked to an individual person within the zone. More information on variation within zones should be sought. Further statistical modelling with smoothing techniques and inclusion of information onfor example, residence time, $\mathrm{pH}$, and temperature-could then be carried out to increase the precision of the water zone means.

The evidence presented here suggests that in this study area an annual water zone mean calculated from routinely collected health data may be a reasonable measure of exposure for a reproductive epidemiological study of those people resident within the zone. However, uncertainties remain. Concentrations of TTHMs were only strongly correlated with chloroform concentrations, and water zone means for other disinfection byproducts of chlorination should be used in the epidemiological study, if possible, to provide more accurate estimates. The situation in other areas of the country where the water supply characteristics are different may not be the same. Also these measures do not take into account personal exposure characteristics. For example, people can move between zones during pregnancy and there will be variation among pregnant women in patterns of water consumption, as well as showering, bathing, and swimming habits. ${ }^{23}$ However, it is possible that these factors are fairly similar on a population level by water zone and that the variation in water zone mean may be the main determinant of uptake of disinfection byproducts of chlorination in the population under study. Further work needs to be carried out to either confirm or refute this.

The Small Area Health Statistics Unit is funded by a grant from the Department of Health, Department of the Environment, Transport and the Regions, Health and Safety Executive, Scottish Office Home and Heath Department, Welsh Office, and Northern Ireland Department of Health and Social Services. The views expressed in this publication are those of the authors and not necessarily of the funding departments.

1 Morris RD, Audet A-M, Angelillo IF, et al. Chlorination, chlorination by-products and cancer: a meta analysis. $A m \mathcal{F}$ Public Health 1992;82:955-63.

2 Reif J, Hatch M, Bracken M, et al. Reproductive and developmental effects of disinfection by-products in drinking water. Environ Health Perspect 1996;104:1056-61.

3 Nieuwenhuijsen MJ, Toledano MB, Eaton NE, et al. Chlorination disinfection by-products in water and their ination disinfection by-products in water and their association with adverse reproductive outcomes, a review. 57:73-85

4 Aschengrau A, Zierler S, Cohen. A Quality of community drinking water and the occurrence of late adverse pregnancy outcomes. Arch Environ Health 1993;48:105-13. 
5 Kanitz S, Franco Y, Patrone V et al. Association between drinking water disinfection and somatic parameters at drinking water disinfection and somatic par
birth. Environ Health Perspect 1996;104:516-20.

6 Bove F, Fulconer M, Klotz J, et al. Public drinking water contamination and birth outcomes. Am $\mathcal{f}$ Epidemiol 1995;9:850-63.

7 Gallagher M, Nuckols J, Stallones L, et al. Exposure to trihalomethanes and adverse reproductive outcomes. Epidemiology 1998;9:484-9.

8 Dodds L, King W, Woolcot C. Trihalomethanes in public water supplies and adverse birth outcomes. Epidemiology 1999;3:233-7.

9 Kramer $M$, Lynch $C$, Isacson $\mathrm{P}$, et al. The association of waterborne chloroform with intrauterine growth retardation. Epidemiology 1992;3:407-13.

10 Klotz JB, Pyrch LA. Neural tube defects and drinking water disinfection by-products. Epidemiology 1999;10:383-90.

11 Savitz D, Andrews K, Pastore L. Drinking water and pregnancy outcome in central North Carolina: source, pregnancy outcome in central North Carolina: source, 1995;103:592-6.

12 Swan S, Waller K, Hopkins B, et al. A prospective study of spontaneous abortion: relation to amount of source of drinking water consumed in early pregnancy. Epidemiology 1997;9:126-33.

13 Waller K, Swan S, DeLorenze, et al. Trihalomethanes in drinking water and spontaneous abortion. Epidemiology 1998;9:134-40

14 Swan S, Waller K. Disinfection by-products and adverse reproductive outcomes: what is the agency and how is it measured? Epidemiology 1998;9:479-81.
15 Smith V, Cech I, Brown J, et al. Temporal variations in rihalomethane concentrations in drinking water. Environ Si Techol 1980;14:190-6.

16 Krasner S, McGuire M, Jacangelo J, et al. The occurrence of disinfection by-products in US drinking water. Fournal of the American Water Works Association 1989;81:41-53.

17 Smith A E. Developmental toxicity of dichloroacetonitrile: a by product of drinking water disinfection. Fundam Appl Toxicol 1989;12:765-72.

18 Box GEP, Cox DR. An analysis of transformations. Fournal of the Royal Statistical Society Series B 1964;26:211-52.

19 Spiegelhalter DJ, Thomas A, Best NG, et al. BUGS 0.5 examples. Vol 1. Cambridge: Medical Research Council Biostatistics Unit, 1997.

20 Chen W, Weisel C. Halogenated DBP concentrations in a distribution system. Fournal of the American Water Works Association 1998;90:151-63.

21 Keegan T. Trihalomethane levels in the North of England 1992-6 [MSc Thesis]. London: Imperial College Centre for Environmental Technology, University of London, 1998 .

22 United States Environmental Protection Agency. Panel report and recommendations for conducting epidemiological research on possible reproductive and developmental effects of exposure to disinfected drinking water. Research Triangle Park, CA: US EPA, 1998.

23 Nieuwenhuijsen M J, Toledano M B, Elliott P. Uptake of chlorination disinfection by-products; a review and a discussion of its implications for exposure assessment in epidemiological studies. Fournal of Exposure Analysis and Environmental Epidemiology 2000;10:586-99.

\section{Open reviewing}

Many journals, including the BMJ, have moved to a system of open reviewing, whereby authors know the names of reviewers of their papers. Research has shown that named reviews, although not of better quality than anonymous reviews, are not of worse quality either. Therefore in the interests of transparency, it seems fair to let authors know who has reviewed their paper. At Occupational and Environmental Medicine we have considered the issue carefully. There are some concerns that reviewers, especially those who are more junior, might feel intimidated and not wish to make negative comments about papers submitted by senior people in the field. On the other hand, some reviewers might hide behind the cloak of anonymity to make unfair criticisms so as to reduce the chances of publication by rivals. We have decided to introduce initially a system of open reviewing if the reviewers agree explicitly. So when a reviewer is sent a paper, he or she is asked to indicate whether we can disclose their name or not when sending the authors their comments. We will be monitoring this to see how many of our reviewers are happy to be named. If it is most of them, we will move to a system of open reviewing as the norm, with a possible "opt out" clause for reviewers. 